\title{
Attitude and Behavioral Intention to Develop and Use MOOCs among Academics
}

\author{
https://doi.org/10.3991/ijet.v14i24.12105 \\ Habibah Ab Jalil ( $\left.{ }^{凶}\right)$, Aini Marina Ma'rof, Rosmaria Omar \\ Universiti Putra Malaysia, Selangor, Malaysia \\ habibahjalil@upm.edu.my
}

\begin{abstract}
Several practice-oriented courses are currently integrated into online learning platforms, providing a new wave of instructional approaches among academics. These include the use of Open CourseWare and Massive Open Online Courses (MOOCs). It is worthwhile to explore how learners respond to new teaching methods when practice-oriented courses are placed online. The primary purpose of this study is to determine levels of attitude and behavioural intention to develop and use MOOCs and the possible relationships between those variables. Participants consisted of 238 academics in a Malaysian public university. Descriptive and Pearson Correlation analyses were employed to determine relationships. Results show that: (a) respondents are receptive towards MOOCs as an alternative platform to deliver teaching content; (b) they are mostly ready to develop MOOCs; (c) they are generally prepared to use MOOCs in teaching and learning and (d) there are significant relationships between academic staffs' attitude and behavioural intention to develop and use MOOCs. The findings of this study are pertinent in understanding MOOCs from the perspective of academics so that proper support can be provided accordingly.
\end{abstract}

Keywords-Online learning, MOOCs, technology acceptance, behavioural intention, intention to develop, intention to use

\section{Introduction}

Two of the ten shifts declared in the National Higher Education Strategic Plan under the Malaysia Education Blueprint 2015-2025 focuses on technology-enabled innovation in making education more accessible and personalised and promoting lifelong learning. One of the underlined strategies for these shifts is through supporting higher learning institutions to develop Massive Open Online Courses (MOOCs) in their respective niche areas and to participate in international MOOC consortiums.

Following the advancements in open educational resources, MOOCs are considered to be a recent innovation in learning with virtual technology-enhanced learning environments, as stated in Ref. [20]. MOOCs are courses offered to the masses by individuals or higher education institutions via an online platform, with or without tuition fees and no pre-requisites. Participants can request certificates upon complet- 
ing the course, with or without the charge depending on the course provider [12]. MOOCs breaks the conventional barriers which allow anyone to enroll in a professional and legitimate course without worrying about the financial costs, distance, and prior educational background [14]. It offers the opportunity for educators to reach to a large number of students worldwide and this open education format attracts larger audiences than traditional online education [2]. Moreover, communities of MOOCs also share common interests. These advantages could be utilised by university academics to enhance their teaching and learning endeavors.

The first MOOC to be offered in Malaysia was in 2013 by Taylor's University for its Entrepreneurship course. Noticing the success of Taylor's, the Malaysian government launched pilot MOOCs in September 2014 shouldered by four public universities: Universiti Putra Malaysia (UPM), Universiti Kebangsaan Malaysia (UKM), Universiti Teknologi MARA (UiTM), and Universiti Malaysia Sarawak (UNIMAS). This enterprise was also taken up by Open University of Malaysia (OUM) where they initiated the development of their own MOOC. With positive feedback from the pilot courses, subsequently, in the same year, Malaysia decided to fast-track the development of MOOCs by becoming the first country in the world to integrate MOOCs in all of its public universities at a national scale through government initiatives [6].

\section{Background of the Study}

Despite the enthusiasm towards MOOCs, a high number of dropout rates from online courses were highly noticeable. On average, less than $10 \%$ of enrolled students complete their MOOC courses [5]. A significant concern has been centered on the quality of teaching and learning by considering the issue of MOOCs dropout and noncompletion [10]. However, the dropout and non-completion rate may not be the best measure to evaluate learning with MOOCs as students enroll in MOOCs for various reasons.

Limited amount of research has been done on the factors that influence MOOCs' continuance intention as Ref. [4] but among the identified predictors were the attitude and behavioural intention of instructors towards MOOCs. This includes perceived attitudes towards MOOCs and the extent to which MOOCs meet the various needs of users. According to [20], Technology Acceptance Model (TAM) consists of two main variables that affect user's intention to adopt the technology, i.e. perceived usefulness and perceived ease to use. Behavioural intentions consequently stimulate actual system use [8].

TAM was found to be valuable in predicting the acceptance of new delivery methods of e-learning systems in education [14]. Researchers have explained MOOCs acceptance or use by extending the TAM range of external factors. Besides, TAM concerns of the short-term belief and attitude before and after the acceptance of MOOCs. However, inadequate research emphasises the intrinsic motivation that drives users to adapt their behaviour and adopt the technology as Ref. [21] and [7].

In line with this current state of affairs, the present study aims to identify the relationship between university academics' attitude and behavioural intention to develop 
and use MOOCs. This study also presents a research framework for integrating the Technology Acceptance Model (TAM). To test the dependent variable of developing and using MOOCs, TAM is applied to examine the relationship between attitude and behavioural intentions. The relationship highlighted in the TAM suggests that attitude serves as an evaluative predisposition to behaviour [1]. Thus, we propose the following research hypotheses:

Ha1: There is a significant relationship between university academics' attitude and behavioural intention to develop MOOCs.

Ha2: There is a significant relationship between university academics' attitude and behavioural intention to use MOOCs.

\section{$3 \quad$ Methodology}

The combination of descriptive and correlational designs for this study offers enhanced understanding on the differentiation, obtained a wide range of information and relationships that exist among independent variables and the dependent variable involved at the university under review. A quantitative approach was used in this study by way of gathering data using a set of questionnaires to test the hypotheses formulated. The instrument was administered in both online and offline forms to maximise response rate. According to Ref. [2], descriptive research determines and reports the way things are; it involves collecting numerical data to answer questions about the current status of the subject of study. Questionnaire development and data collection procedures are discussed in the subsequent sections.

\subsection{Sampling technique}

Convenience sampling was used in this research. The respondent is drawn based on their convenience. Convenience sampling is a type of nonprobability sampling in which people are sampled simply because they are "convenient" sources of data for researchers. Sample of this study consisted of university academics who involved in developing and using MOOCs for their teaching and learning and their willingness to participate in this research. They are typical university academics who teach university courses to students enrolling in their classes.

\subsection{Data collection}

The study was designed to determine academics' attitude and behavioural intention to develop and use MOOCs, and to investigate the relationship between the independent and dependent variables. The target participants of this study were the university's faculty members. In this study, Cochran's formula was used to determine sample size. The data gathered using a Likert-scale questionnaire were sent to respondents through online and offline. A survey was used to collect data from 238 staffs who practiced MOOCs in their teaching and learning. Meanwhile, the respondents were defined as those who practiced MOOCs and had experience in using MOOCs. 


\subsection{Questionnaire development}

This study used a set of questionnaires consisting of two main sections: attitude towards MOOCs and behavioural intention to develop and use MOOCs. Each item corresponding to the constructs was measured using a five-point Likert scale, one indicating "strongly disagree" and 5 "strongly agree". Participants answered the survey questions according to their self-perception. Altogether 15 items have been used to measure attitude towards MOOCs. The instrument was adapted from Kim, .et. al (2010); Chang (2010); and Wu and Chen (2017) as Ref [13]; [10] and [20]. Meanwhile, the instrument for behavioural intention to develop and use MOOCs was adapted from Yang and Su (2017) as Ref. [21].

Table 1. A Survey Items and References

\begin{tabular}{|l|l|c|l|}
\hline \multicolumn{1}{|c|}{ Construct } & \multicolumn{1}{|c|}{ Sub-construct } & $\begin{array}{c}\text { Total } \\
\text { items }\end{array}$ & \multicolumn{1}{|c|}{ References } \\
\hline $\begin{array}{l}\text { Behavioural intention to } \\
\text { develop and use MOOCs }\end{array}$ & $\begin{array}{l}\text { Behavioural intention to } \\
\text { develop MOOCs }\end{array}$ & 8 & Yang \& Su, 2017 \\
\cline { 2 - 4 } & $\begin{array}{l}\text { Behavioural intention to } \\
\text { use MOOCs }\end{array}$ & 8 & Yang \& Su, 2017 \\
\hline Attitude towards MOOCs & No sub construct & 15 & $\begin{array}{l}\text { Kim, T., Suh, Y. K., Lee, G., \& Choi, B. } \\
\text { G. (2010); Chang, H. H. (2010); \& Wu, B., } \\
\text { \& Chen, X. (2017). }\end{array}$ \\
\hline
\end{tabular}

\subsection{Reliability and validity of the instrument}

Reliability is defined as how consistent a measuring device is. Besides, a measurement is deemed reliable or consistent when similar results can be replicated in similar circumstances. To establish the reliability of the analysis of this study, the Cronbach Alpha value of $\leq 0.60$ is considered to be not reliable, while more than $\geq$ 0.70 indicates that it is highly acceptable. The reliability analyses for this research are tabulated in Table 2.

Table 2. Reliability Analysis of Construct

\begin{tabular}{|l|c|c|}
\hline \multicolumn{1}{|c|}{ Constructs } & Number of Items & Alpha Cronbach \\
\hline Attitude Towards MOOCs & 15 & 0.814 \\
\hline Behavioural Intention to Develop MOOCs & 8 & 0.807 \\
\hline Behavioural Intention to Use MOOCs & 8 & 0.851 \\
\hline
\end{tabular}

\section{$4 \quad$ Results}

The university's academics as participants responded to the constructs of attitude towards MOOCs and behavioural intention to develop and use MOOCs. Mean, standard deviation and agreement percentage scores based on a 5 Likert scale were calculated for the constructs. IBM SPSS Statistics 22 was used in this study to run the descriptive and correlational analyses. 


\subsection{Results of attitude towards MOOCs}

Descriptive analyses have been used to analyse attitudes towards MOOCs among the respondents, measured by 15 items. The results for each item were presented in Table 3. Findings in Table 3 shows that item 3 "I am glad there are more options to learn these days with MOOCs" has the highest mean $\mathrm{M}=4.56, \mathrm{SD}=.67$, with the degree of "agree" at $66 \%, \mathrm{~N}=157$ respondents "strongly agree", and $25.2 \%, \mathrm{~N}=60$ respondents "agree" with the statement. The results demonstrate that through MOOCs, respondents are happy as they were given alternative options to make their teaching and learning experience more meaningful. Item 5, "I do not like talking with others about MOOCs" has shown the lowest mean, $\mathrm{M}=2.99, \mathrm{SD}=.54$ with the degree of "agree" at $78.2 \%$, followed by "neutral" and "disagree" with $10.1 \%$ respectively. This goes to show that while academics are receptive of MOOCs and the various potentials it offers in teaching and learning, the majority of the respondents are neutral when it comes to discussing MOOCs with others.

\subsection{Behavioral intention to develop and use MOOCs}

To analyse behavioural tendencies to develop and use MOOCs among academics, descriptive analyses were run on the two constructs (i.e. a) to develop MOOCs and b) to use MOOCs measured by 16 items. The results for each sub construct are presented in Table 4.

Table 3. Descriptive Analyses for Attitude towards MOOCs among Academics

\begin{tabular}{|c|c|c|c|c|c|c|c|c|c|c|c|c|c|}
\hline \multirow{3}{*}{ No. } & \multirow{3}{*}{ Item } & \multirow{3}{*}{$\mathbf{M}$} & \multirow{3}{*}{ SD } & \multicolumn{10}{|c|}{ Scale of Agreement } \\
\hline & & & & \multicolumn{2}{|c|}{1} & \multicolumn{2}{|c|}{2} & \multicolumn{2}{|r|}{3} & \multicolumn{2}{|c|}{4} & \multicolumn{2}{|c|}{5} \\
\hline & & & & $f$ & $\%$ & $f$ & $\%$ & $f$ & $\%$ & $f$ & $\%$ & $f$ & $\%$ \\
\hline 1. & MOOCs does not scare me at all. & 4.31 & 1.06 & 4 & 1.7 & 18 & 7.6 & 30 & 12.6 & 32 & 13.4 & 154 & 64.7 \\
\hline 2. & MOOCs makes me feel uncomfortable. & 3.54 & .83 & 6 & 2.5 & 33 & 13.9 & 28 & 11.8 & 168 & 17.6 & 3 & 1.3 \\
\hline 3. & $\begin{array}{l}\text { I am glad there are more options to learn these } \\
\text { days with MOOCs. }\end{array}$ & 4.56 & .67 & 0 & 0.0 & 2 & .8 & 29 & 8.0 & 60 & 25.2 & 157 & 66.0 \\
\hline 4. & $\begin{array}{l}\text { I am glad there are more options to teach these } \\
\text { days with MOOCs. }\end{array}$ & 4.32 & 1.03 & 4 & 1.7 & 16 & 6.7 & 30 & 12.6 & 37 & 15.5 & 151 & 63.4 \\
\hline 5. & I do not like talking with others about MOOCs. & 2.99 & .54 & 3 & 1.3 & 24 & 10.1 & 186 & 78.2 & 22 & 9.2 & 3 & 1.3 \\
\hline 6. & Using MOOCs is enjoyable. & 4.28 & 1.04 & 0 & 0.0 & 22 & 9.2 & 38 & 16.0 & 27 & 11.3 & 151 & 63.4 \\
\hline 7. & I dislike using MOOCs in teaching. & 3.21 & .50 & 0 & 0.0 & 5 & 2.1 & 182 & 76.5 & 46 & 19.3 & 5 & 2.1 \\
\hline 8. & I dislike using MOOCs in learning. & 3.05 & .58 & 6 & 2.5 & 14 & 5.9 & 182 & 76.5 & 33 & 13.9 & 3 & 1.3 \\
\hline 9. & Using MOOCs saves time. & 3.58 & .81 & 6 & 2.5 & 26 & 10.9 & 34 & 14.3 & 166 & 69.7 & 6 & 2.5 \\
\hline 10. & $\begin{array}{l}\text { University would be a better place without } \\
\text { MOOCs. }\end{array}$ & 3.76 & .70 & 5 & 2.1 & 11 & 4.6 & 30 & 12.6 & 180 & 75.6 & 12 & 5.0 \\
\hline 11. & $\begin{array}{l}\text { Students must use MOOCs in all subject mat- } \\
\text { ters. }\end{array}$ & 4.45 & .68 & 17 & 7.1 & 37 & 15.5 & 172 & 72.3 & 9 & 3.8 & 3 & 1.3 \\
\hline 12. & Learning about MOOCs is a waste of time. & 4.29 & 1.08 & 4 & 1.7 & 18 & 7.6 & 36 & 15.1 & 26 & 10.9 & 154 & 64.7 \\
\hline 13. & $\begin{array}{l}\text { MOOCs would motivate students to do more } \\
\text { study. }\end{array}$ & 3.61 & .92 & 3 & 1.3 & 6 & 2.5 & 36 & 15.1 & 36 & 15.1 & 157 & 66.0 \\
\hline 14. & MOOCs is a fast means of getting knowledge. & 4.29 & .77 & 6 & 2.5 & 20 & 8.4 & 32 & 13.4 & 173 & 72.7 & 7 & 2.9 \\
\hline 15 . & I would avoid MOOCs as much as possible & 3.81 & .54 & 1 & .4 & 7 & 2.9 & 35 & 14.7 & 188 & 79.0 & 7 & 2.9 \\
\hline
\end{tabular}


Table 4. Descriptive Analysis for Behavioral Intention to Develop and Use MOOCs

\begin{tabular}{|c|c|c|c|c|c|c|c|c|c|c|c|c|c|}
\hline \multirow{3}{*}{ No. } & \multirow{3}{*}{ Item } & \multirow{3}{*}{$\begin{array}{c}\text { Me } \\
\text { an }\end{array}$} & \multirow{3}{*}{ SD } & \multicolumn{10}{|c|}{ Scale of Agreement } \\
\hline & & & & \multicolumn{2}{|c|}{1} & \multicolumn{2}{|c|}{\begin{tabular}{|l|l|}
2 & \\
\end{tabular}} & \multicolumn{2}{|c|}{\begin{tabular}{|l|}
3 \\
\end{tabular}} & \multicolumn{2}{|c|}{4} & \multicolumn{2}{|c|}{5} \\
\hline & & & & $f$ & $\%$ & $f$ & $\%$ & $f$ & $\%$ & $f$ & $\%$ & $f$ & $\%$ \\
\hline \multicolumn{14}{|c|}{ Behavioural intention to develop MOOCs } \\
\hline 1. & $\begin{array}{l}\text { I predict that I will develop MOOCs in } \\
\text { the next } 6 \text { months. }\end{array}$ & 2.46 & .86 & 0 & 0.0 & 186 & 74.4 & 23 & 9.2 & 30 & 12.0 & 11 & 4.4 \\
\hline 2. & $\begin{array}{l}\text { I affirm that developing teaching materi- } \\
\text { als in MOOCs is a reasonable effort that } \\
\text { should be followed by other lecturers in } \\
\text { the university shortly. }\end{array}$ & 3.88 & .52 & 0 & 0.0 & 8 & 3.2 & 26 & 10.4 & 203 & 81.2 & 13 & 5.2 \\
\hline 3. & $\begin{array}{l}\text { I intend to work in developing MOOCs in } \\
\text { the next } 12 \text { months. }\end{array}$ & 2.52 & .91 & 0 & 0.0 & 180 & 72.0 & 22 & 8.8 & 36 & $\mid 14.4$ & 12 & 4.8 \\
\hline 4. & $\begin{array}{l}\text { I am looking forward to attend training } \\
\text { sessions to learn about how to develop } \\
\text { MOOCs in more depth. }\end{array}$ & 3.74 & .73 & 7 & 2.8 & 13 & 5.2 & 25 & $10.0 \mid$ & 196 & 78.4 & 9 & 3.6 \\
\hline 5. & I will not develop MOOCs in future. & 2.23 & .70 & 13 & 5.2 & 189 & 75.6 & 28 & 11.2 & 17 & 6.8 & 3 & 1.2 \\
\hline 6. & $\begin{array}{l}\text { I am not planning to develop MOOCs } \\
\text { often. }\end{array}$ & 3.76 & .69 & 6 & 2.4 & 11 & 4.4 & 27 & 10.8 & 198 & 79.2 & 8 & 3.2 \\
\hline 7. & $\begin{array}{l}\text { I am thinking of developing MOOCs for } \\
\text { teaching activities. }\end{array}$ & 3.90 & .47 & 0 & 0.0 & 5 & 2.0 & 26 & $|10.4|$ & 207 & 82.8 & 12 & 4.8 \\
\hline 8. & $\begin{array}{l}\text { I am planning to develop MOOCs in my } \\
\text { teaching activities. }\end{array}$ & 3.87 & .53 & 1 & 0.4 & 7 & 2.8 & 26 & $10.4 \mid$ & 204 & 81.6 & 12 & 4.8 \\
\hline \multicolumn{14}{|c|}{ Behavioural intention to use MOOCs } \\
\hline 1. & $\begin{array}{l}\text { I predict that I will be using MOOCs in } \\
\text { the next } 6 \text { months. }\end{array}$ & 3.86 & .55 & 0 & 0.0 & 10 & 4.0 & 28 & 11.2 & 198 & 79.2 & 14 & 5.6 \\
\hline 2. & $\begin{array}{l}\text { I affirm that using MOOCs is a good } \\
\text { effort that should be followed by other } \\
\text { lecturers in the university in the near } \\
\text { future. }\end{array}$ & 3.89 & .50 & 0 & 0.0 & 6 & 2.4 & 28 & 11.2 & 202 & 80.8 & 14 & 5.6 \\
\hline 3. & $\begin{array}{l}\text { I intend to work with MOOCs in the next } \\
12 \text { months. }\end{array}$ & 3.90 & .50 & 0 & 0.0 & 6 & 2.4 & 28 & 11.2 & 201 & 80.4 & 15 & 6.0 \\
\hline 4. & $\begin{array}{l}\text { I am looking forward to attend training } \\
\text { sessions to learn about the usage of } \\
\text { MOOCs in more depth }\end{array}$ & 3.72 & .71 & 6 & 2.4 & 14 & 5.6 & 31 & $|12.4|$ & 192 & 76.8 & 7 & 2.8 \\
\hline 5. & I will not use MOOCs in future. & 3.83 & .53 & 1 & .4 & 7 & 2.9 & 31 & 12.9 & 193 & 80.4 & 8 & 3.3 \\
\hline 6. & I am not planning to use MOOCs often. & 3.63 & .75 & 6 & 2.5 & 20 & 8.3 & 32 & 13.3 & 180 & 75.0 & 2 & .8 \\
\hline 7. & $\begin{array}{l}\text { I am thinking of using MOOCs for teach- } \\
\text { ing activities. }\end{array}$ & 3.92 & .40 & 0 & 0.0 & 0 & 0.0 & 31 & $|12.4|$ & 207 & 82.8 & 12 & 4.8 \\
\hline 8. & $\begin{array}{l}\text { I am planning to use MOOCs in my } \\
\text { teaching activities. }\end{array}$ & 3.96 & .32 & 0 & 0.0 & 0 & 0.0 & 18 & 7.2 & 224 & 89.6 & 8 & 3.2 \\
\hline
\end{tabular}

The highest mean score for the sub-construct on behavioural intention to develop MOOCs is for item 7, "I am thinking of developing MOOCs for teaching activities" $(\mathrm{M}=3.90, \mathrm{SD}=.47) .82 .8 \%$ of the respondents agreed that they are interested in developing the MOOC platform as one of their learning activities for students. This demonstrates that academics have purposive intentions to use MOOCs in their teaching and learning activities despite a majority reporting that they do not foresee themselves as being able to develop MOOCs within the next six months (Item 1, Mean=2.46, SD $=86$ ). Item 5, "I will not develop MOOCs in future" indicates the lowest mean, $\mathrm{M}=2.23, \mathrm{SD}=.70$ suggesting that respondents are particularly interested in developing 
MOOCs as one of the means to assist them in their instructional delivery. Under the sub-construct of behavioural intention to use MOOCs, Item 8, "I am planning to use MOOCs in my teaching activities" was noted as the highest mean, $\mathrm{M}=3.96, \mathrm{SD}=.32$ with the degree of "agree" at $93.0 \%$. This shows that majority of the respondents are ready to use MOOCs as an alternative for instructional delivery. Item 4 "I am looking forward to attending training sessions to learn about the usage of MOOCs in more depth" shows that academics are also willing to attend related workshops on the development and delivery of MOOCs $(\mathrm{M}=3.72, \mathrm{SD}=.71)$.

\subsection{Relationships between academic's attitude and behavioral intention to develop and use MOOCs}

Correlational analyses were used to examine the relationship between academic staffs' attitude and behavioural intention to develop MOOCs.

Table 5. Correlation Matrix between Staff's Attitude and Behavioral Intention to Develop and Use MOOCs

\begin{tabular}{|l|c|c|c|}
\hline & $\begin{array}{c}\text { Attitude toward } \\
\text { MOOCs }\end{array}$ & $\begin{array}{c}\text { Behavioural Intention } \\
\text { to Develop MOOCs }\end{array}$ & $\begin{array}{c}\text { Behavioural Inten- } \\
\text { tion to use MOOCs }\end{array}$ \\
\hline Attitude toward MOOCs & 1 & 1 & \\
\hline Behavioral Intention to Develop MOOCS & $.703^{* *}$ & $.519^{* *}$ & \\
\hline Behavioral Intention to Use MOOCS & $.434^{* *}$ & 1 \\
\hline
\end{tabular}

Significant at level ***, $\mathrm{p}=.000$

Results indicated that there is a significant positive relationship between attitude towards MOOCs and behavioural intention to develop MOOCs, $r=.703, p=.000$ and a significant positive correlation between attitude towards MOOCs and behavioural to use MOOCs, $\mathrm{r}=.434, \mathrm{p}=.000$. Therefore, $\mathrm{H} 1$ and $\mathrm{H} 2$ are supported. The result also shows there is a significant relationship between behavioural intention to develop MOOCs and behavioural intention to use MOOCs, $\mathrm{r}=.519, \mathrm{p}=.000$. This result that all measured variables are correlated with each other. In other words, if the attitude towards MOOCs among the academic staffs is high, their behavioural intention to develop and use MOOC will also be high.

\section{Discussion}

Overall, positive results were obtained for the attitude and behavioural intention to develop and use MOOCs. The results indicate that attitude towards MOOCs among the academics is correlated to intention to create and use of MOOCs as a viable means of instructional delivery. The large majority decided that MOOC is an efficient platform for instructional delivery that aligns well with the current development of technologies. Respondents were also eager to develop their own MOOCs as an initiative to improve students' learning engagement. These results can be linked to the study by Cassandra and Gregory as Ref. [9] who studied the effects of video lectures in MOOCs when compared to face-to-face lectures. The MOOC lectures contained pre- 
recorded teaching videos where the instructors were present in the lectures as 'talkingheads'. They discovered that by using talking heads, an unexpected intimate tutorial space was created - as if the lecturers were speaking directly to them. In another study, Ref. [16] and [15] revealed that students were more engaged in learning via talking-heads rather than PowerPoint slides. Linking back to the present findings, most of the respondents are willing to use MOOC platforms, indicating that MOOCs are believed to be useful in aiding conceptual understanding during the teaching and learning process as stated by Ref. [3] and [11]. However, the intention aspect should be explored further as it shows that there are tendencies of academics to terminate the use of MOOCs. This is because there are cases of insufficient facilities and poor connectivity within the respective institutions.

Significant moderate relationships were demonstrated from the correlation matrix between the academic's attitude and behavioural intention to develop and use MOOCs. From the findings, it can be inferred that academics have purposive intentions to develop and use MOOCs as a means for teaching and learning. This implies that practitioners, i.e. academics, should be aware that sustained intention to use MOOCs depends not only on attitude towards MOOCs but also on perceived usefulness of MOOCs itself. The continuance intention of academics to develop and use MOOCs can be enhanced by improving their beliefs in the effectiveness and efficiency of MOOCs in teaching and learning. These findings indicate that it is not enough to build MOOCs with a modern, state-of-the-art interface to influence users' continuance intention, but we must also prioritise on highlighting its useful functions over ease of use [20].

\section{Recommendations for Future Research}

This research was conducted at one of a public university in Malaysia where MOOCs are developing rapidly. However, there is still a long way to go to get more academics to be on board. Thus, survey respondents at the time this research was conducted participated in their own volition, which may reflect a self-selection bias [20]. As the population of MOOC users increases, the ability to perform random probabilistic sampling will also improve. Second, this research was conducted as a cross-sectional study. User behaviour, however, is dynamic. Therefore, the longitudinal analysis may provide better insight into the development of user behaviour. It is also necessary to gather longitudinal evidence if we are to deepen our understanding of the interrelationships to technology acceptance. As such, a longitudinal research design is a potential avenue for future research. Third, future research must examine other constructs, which are related to MOOC features and social motivation constructs an inability to measure perceived to develop and use MOOCs. The attitude in MOOCs is relatively new to researchers. The findings and implications presented in this study must be generalised for external validity because they were obtained from only a single study that examined MOOCs and targeted a specific user group in one particular university. Further research is expected to help generalise the findings and discussions to include different cultures in which MOOCs are utilized. 


\section{Conclusion}

This study considers the potential differences among academics of Malaysian institutions of higher education in terms of attitude and intention to develop and use MOOCs for teaching and learning purposes. Our results indicate that academics' views are associated with their behavioural intentions to create and use MOOCs during their teaching sessions. These results resonate previous findings as stated in Ref. [16];[17];[18] and [19] where strong relationships were found between the variables. Taken together, the results suggest that MOOC developers can increase their efforts to polish further their systems in capturing how curriculum design, assignment types influence MOOC learners, and different interactions so that MOOC platforms can continuously evolve to remain as an attractive alternative for academics to utilise as a viable teaching and learning tool.

\section{Acknowledgement}

This study was supported by research funds from Universiti Putra Malaysia [Project Number: GP-IPS/2017/9555100]. We would also like to acknowledge the contributions of the research assistants who have aided the research team in gathering data and putting this report together.

\section{References}

[1] Ajzen, I. (1985). From intentions to actions: a theory of planned behaviour. In J. Kuhl, \& J. Beckmann (Eds.), Action-control: from cognition to behaviour (pp.11-39). Berlin Heidelberg: Springer. https://doi.org/10.1007/978-3-642-69746-3_2

[2] Alario-Hoyos, C., Perez-Sanagustin, M., Delgado-Kloos, C., Parada, H. A., \& MunozOrganero, M. (2014). Delving into participants' profiles and use of social tools in MOOCs. IEEE Transactions on Learning Technologies, 7(3), 260-266. https://doi.org/10.1109/tlt.20 14.2311807

[3] Al-rahmi, W., \& Aldraiweesh, A. (2019). Data in Brief Massive Open Online Courses ( MOOCs ): Data on higher education. Data in Brief, 22(1), 118-125. https://doi.org/10.10 16/j.dib.2018.11.139

[4] Barnes, S. J. (2011). Understanding use continuance in virtual worlds: Empirical test of a research model. Information \& Management, 48(8), 313-319. https://doi.org/10.1016/j.im. $\underline{2011.08 .004}$

[5] Bartolomé, A., \& Steffens, K. (2015). Are MOOC Promising Learning Environments?

[6] Blueprint, M. E. Blueprint 2015-2025 (Higher Education) (2015). Ministry of Higher Education Malaysia.

[7] Bralic, A., \& Divjak, B. (2018). Integrating MOOCs in traditionally taught courses: achieving learning outcomes with blended learning. International Journal of Educational Technology in Higher Education, 15(2). https://doi.org/10.1186/s41239-017-0085-7

[8] Buchanan, T., Sainter, P., \& Saunders, G. (2013). Factors affecting faculty use of learning technologies: Implications for models of technology adoption. Journal of Computing in Higher education, 25(1), 1-11. https://doi.org/10.1007/s12528-013-9066-6 
[9] Cassandra, D., \& Gregory, L. (2014). Online Versus Face to face: Does Delivery Method Matter for Undergraduate Business School Learning? Business Education \& Accreditation, $6(1)$.

[10] Chang, H. H. (2010). Task-technology fit and user acceptance of online auction. International Journal of Human-Computer Studies, 68(1-2), 69-89. https://doi.org/10.1016/j.ijhcs. 2009.09.010

[11] Eileen, S., McAndrew, Patrick, \& O'Shea, T. (2015). Designing for Educational Technology to Enhance the Experience of Learners in Distance Education: How Open Educational Resources, Learning Design and Moocs Are Influencing Learning. Journal of Interactive Media in Education, 1(6). https://doi.org/10.5334/jime.al

[12] Hill, P. (2012). Online Educational Delivery Models: A Descriptive View. Journal of Educational Technology, 47(6), 84-86.

[13] Kim, T., Suh, Y. K., Lee, G., \& Choi, B. G. (2010). Modelling roles of task-technology fit and self-efficacy in hotel employees' usage behaviours of hotel information systems. International Journal of Tourism Research, 12(6), 709-725. https://doi.org/10.1002/jtr.787

[14] Kalman, Y. M. (2014). A race to the bottom: MOOCs and higher education business models. Open Learning: The Journal of Open, Distance and e-Learning, 29(1), 5-14. https:// doi.org/10.1080/02680513.2014.922410

[15] Li, J. (2017). Construction of Modern Educational Technology MOOC Platform Based on Courseware Resource Storage System State of the art. International Journal of Educational Technology, 12(9), 105-116. https://doi.org/10.3991/ijet.v12i09.7491

[16] Norazah, N., Helmi, N., \& Mohamad Amin, E. (2016). Technology Acceptance of Massive Open Online Courses in Malaysia. Malaysian Journal of Distance Education, 17(2), $1-16$.

[17] Nordin, N., Norman, H., \& Embi, M. A. (2016). Technology Acceptance of Massive Open Online Courses in Malaysia. Malaysian Journal of Distance Education, 17(2), 1-16.

[18] Sukhminder Kaur, M., Goh, W. W., \& Kng, P. G. (2017). Redesigning Learning for Greater Social Impact. Redesigning Learning for Greater Social Impact (August). https://doi. org/10.1007/978-981-10-4223-2_3

[19] Taylor, M. (2017). Redesigning Learning for Greater Social Impact. Redesigning Learning for Greater Social Impact (August). https://doi.org/10.1007/978-981-10-4223-2

[20] Wu, B., \& Chen, X. (2017). Continuance intention to use MOOCs: Integrating the technology acceptance model (TAM) and task technology fit (TTF) model. Computers in Human Behavior, 67, 221-232. https://doi.org/10.1016/j.chb.2016.10.028

[21] Yang, H., \& Su, C. (2017). International Review of Research in Open and Distributed Learning Learner Behaviour in a MOOC Practice-oriented Course: An Empirical Study Integrating TAM and TPB, 18(5). https://doi.org/10.19173/irrodl.v18i5.2991

\section{Authors}

Habibah Ab Jalil is an academic at the Faculty of Educational Studies, Universiti Putra Malaysia (UPM) since 2000. She is an instructor for courses related to information and communication technology (ICT) in education for graduate and undergraduate students. In 2016, she was assigned as the lead researcher for a national study on MOOC which has significant impact on UPM and the country at large. She was involved in the development of various national policies including the National policy on e-Learning (DePAN) and DePAN 2.0, Malaysian MOOC Development 
Guideline, National Open Educational Resources and National Gamification. At the university level, she was a Coordinator and Associate Fellow of Teaching and Learning Innovation Division, Centre for Academic Development (CADe), UPM, in which she particularly coordinated programs and research related to SCL, Blended Learning, LMS, MOOC and OER. She is also the Technology Coordinator of Putra Future Classroom (PFC), Faculty of Educational Studies, undertaking the role in its establishment and strategizing the operation and direction of the first PFC in UPM.

Aini Marina Ma'rof is currently a senior lecturer in Educational Psychology at the Faculty of Educational Studies, Universiti Putra Malaysia (UPM) where she teaches and conducts research in the area of Cognitive Sciences of Teaching and Learning. Her research areas include investigating moment-by-moment learning, measuring cognitive performance across the lifespan, evaluating collaborative learning processes, analyzing argumentation and reasoning, and promoting emergent literacy skills among underserved populations. Since 2016 , she is also actively involved in advancing use of ICT-driven innovation in higher education teaching and learning where she served as the University's MOOC Coordinator, which includes managing and providing professional development courses for academics and technical staffs across the UPM campus on the development, delivery and maintenance of its MOOC courses. She was also a fellow of UPM's Center for Academic Development for its Innovative Teaching and Learning Division, and was a member of its e-Learning Committee, having headed the portfolio on quality assurance of e-content, overseeing quality assurance, content authenticity and credit transfer eligibility of the MOOC courses. At the national level, she was directly involved in the development of the MOOC credit transfer guideline for Malaysian institutions of higher education. She has also developed her own MOOC, Educational Psychology: Understanding the Science of Human Learning.

Rosmaria Omar is currently a researcher in Department of Foundations of Education, Universiti Putra Malaysia. She conducts research in Educational Technology and Psychology.

Article submitted 2019-09-26. Resubmitted 2019-10-26. Final acceptance 2019-10-27. Final version published as submitted by the authors. 